\title{
Di ANA Technique for lipo marking. Adaptable Natural Abdominal Distraction. (For its' acronym in Spanish)
}

\author{
Benavides $\mathrm{A}^{1}$, Villasana $\mathrm{D}^{2}$, Olivares $\mathrm{J}^{2}$ and Torres $\mathrm{E}^{3}$ \\ ${ }^{1}$ Department of Cosmetic Surgery, Napoles Clinic Director, Mexico \\ ${ }^{2}$ Department of Cosmetic Surgery, Napoles Clinic Medical Director, Mexico \\ ${ }^{3}$ Department of Aesthetic Surgery, Instituto de Estudios superiores en Medicina, Mexico Nurse surgical Assistant, Mexico \\ *Corresponding author: Benavides Adán, Department of Cosmetic Surgery, Napoles Clinic Director, Mexico \\ Submission: February 07, 2018; Published: February 27, 2018
}

\begin{abstract}
Overview
The traditional treatment of liposuction involves the removal of the deeper layers of fat. However, the superficial liposuction takes place in an attempt to improve the abdominal contour. With mechanical assisted liposuction and vibroliposuction, using a very narrow cannula in the supra aponeurotic deep and superficial fat planes, a natural appearance is obtained thanks to tissue retraction.
\end{abstract}

Keywords: Liposuction; Natural adaptable abdominal distraction Di ANA (For its acronym in Spanish); vibroliposuction

\section{Introduction}

The discovery of liposuction surges in need of trying to find solutions to lipodystrophies, avoiding extensive scars. In 1921 Dujarrier was awarded for being the first to do liposuction. The innovators of the concept of liposuction, as well as the material for carrying it out, were the surgeons Schrudde, Meyer, Arpad and Giorgio Fischer in 1974. In 1977, Illouz adapted a uterine Karman cannula adding suction to the practice of the process. In 1985 the introduction of syringe-assisted liposuction popularized by Fournier, partly simplified the intervention $[1,2]$.

\section{Material and Methods}

Liposuction is a surgical body contouring surgery group technique. It consists in the removal of fatty tissue in an area of the body through the use of blunt suction cannulas with a small diameter, based on the shrinking properties of skin that attaches to the reduction of the FAT volume when healing $[3,4]$. Currently, the procedure is performed using local infiltration, mechanical assisted liposuction and vibroliposuction; that allow the removal of fatty tissue volumes with less risk for the patient [5-7].

On the women body contouring procedures, Adaptative Abdominal distraction (Di ANA) natural for lipo marking will produce adhesions in the flat aponeurotic muscle in the postoperative period, faking muscle with exercise, by removing excess fat deposits and is able to naturally hide new contours of the body.

The retraction but not contraction will show the surgical outcome. The most important thing is not what is extracted [3], but what is left and way as stops for that thin skin that is covered by a subcutaneous tissue, causing a harmonious and aesthetic retraction.

\section{Technique}

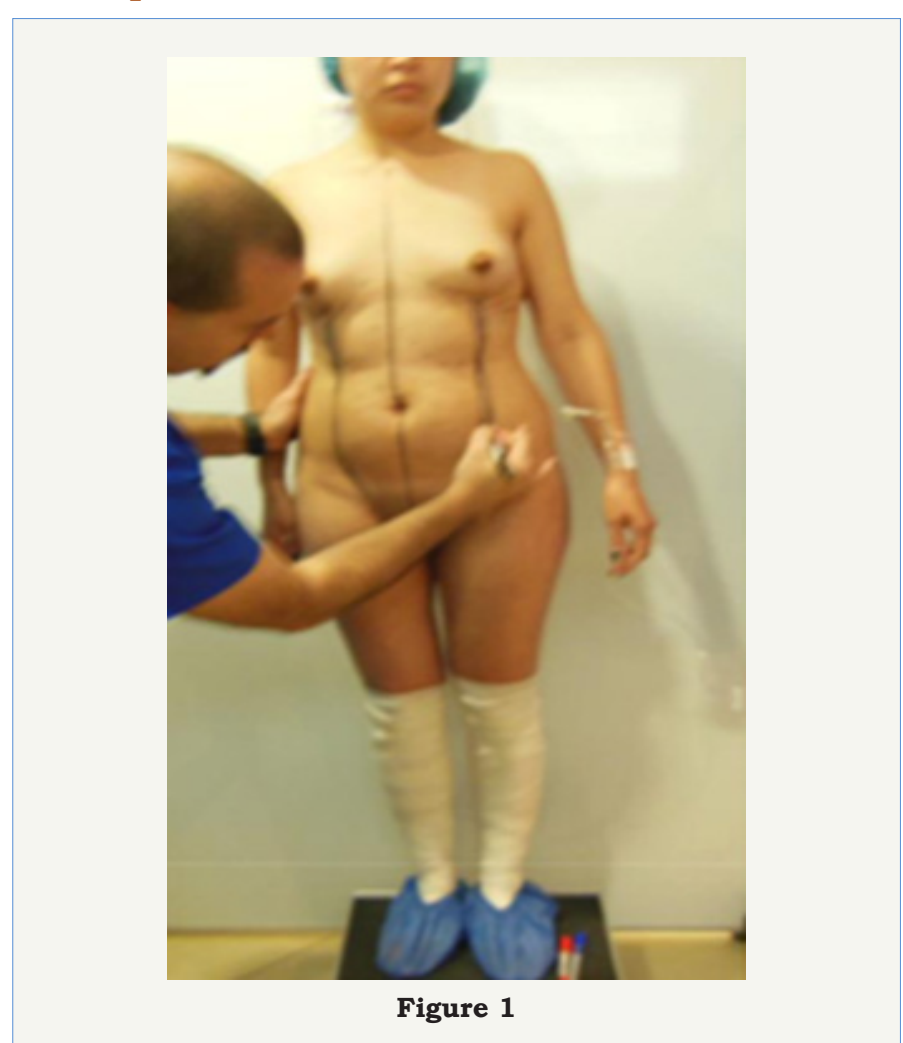


In standing relaxed position and with dynamic contraction, we can appreciate and mark the displacement of the adipose tissue (Figure $1 \& 2$ ).

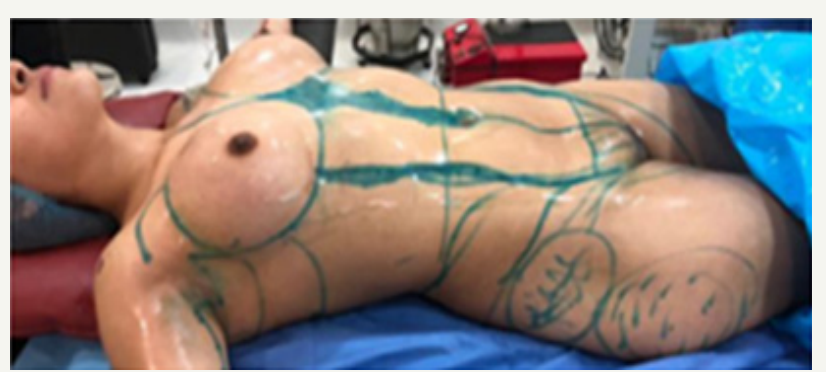

Figure 2

Prior assessment by anesthetic and cardiovascular specialists, while under the effects of high epidural blockage, with the patient in decubitus dorsalis, maneuvers of asepsis and antisepsis are carried out, whit final placement of sterile fields. Using a $1000 \mathrm{cc}$ of saline solution with $1 \mathrm{gr}$ of epinephrine, the abdomen and flanks are infiltrated with a $3 \mathrm{~mm}$ cannula [8]. It was considered that the maximum extracted volume without significant risk of a blood transfusion, was around 2.5 liters thanks to the addition of the infiltrated solution.

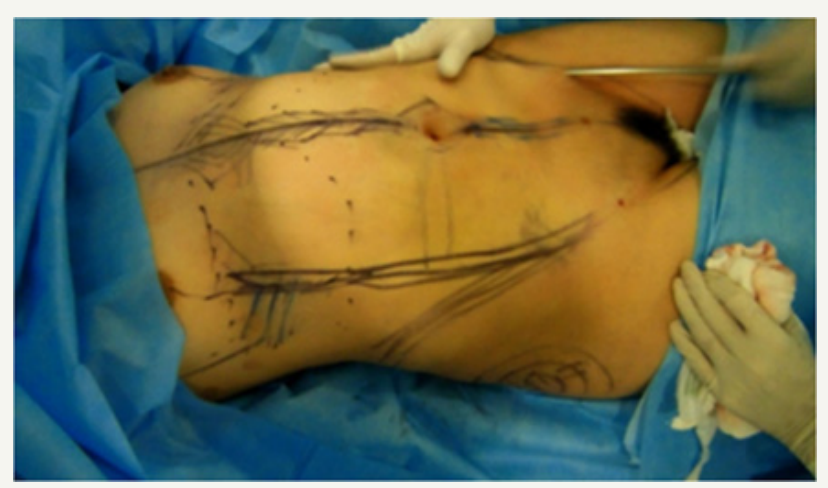

Figure 3

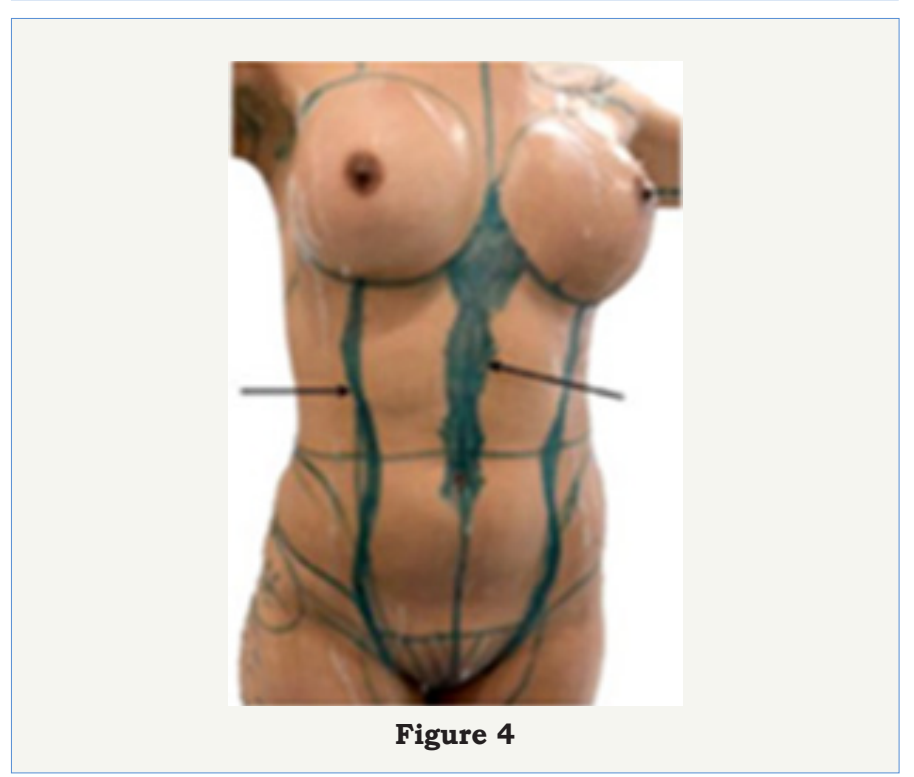

With the use of systematic infiltration with epinephrine it may exceed this volume with security (Figure 3 ). For the performance of the Di ANA technique, three reference lines are made. The first two lines go from the right and left anterior iliac thorns towards its respective coastal arcs and the third line goes from the navel towards the sternum. Lipomarking in then made by working on the supra aponeurotic plane (Figure $4 \& 5$ ). The procedure starts suction the fat in the deep drawing (Figure 6). Then more superficial levels (Figure 7).

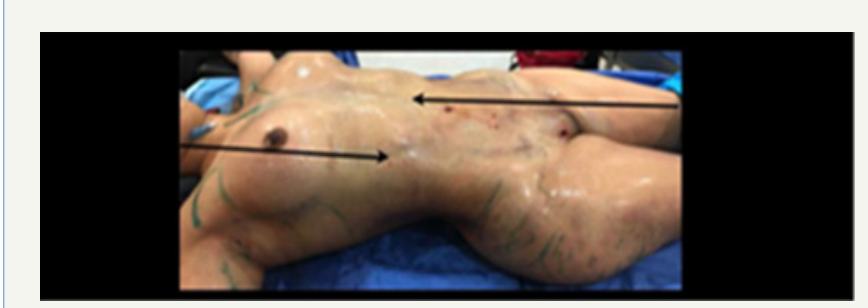

Figure 5

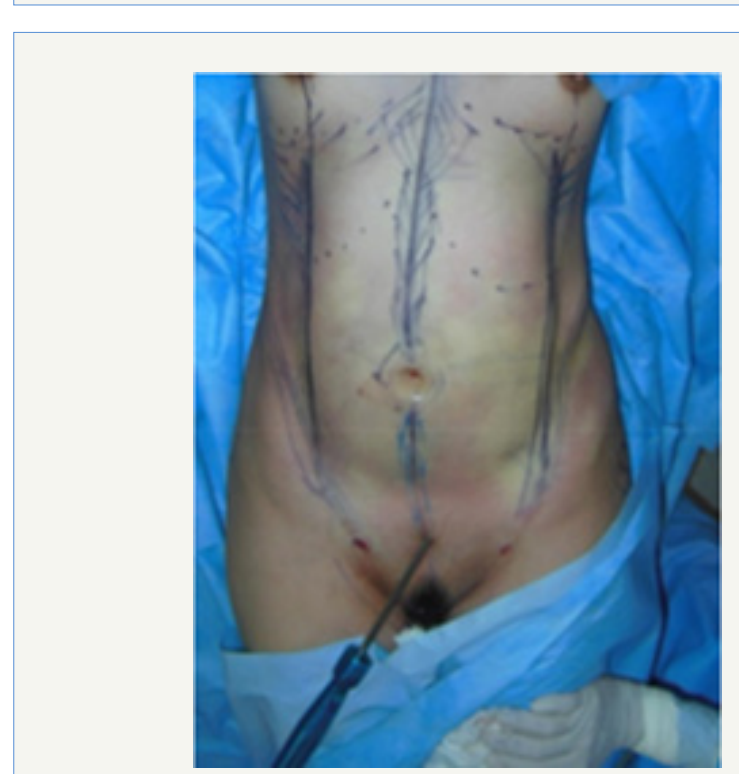

Figure 6

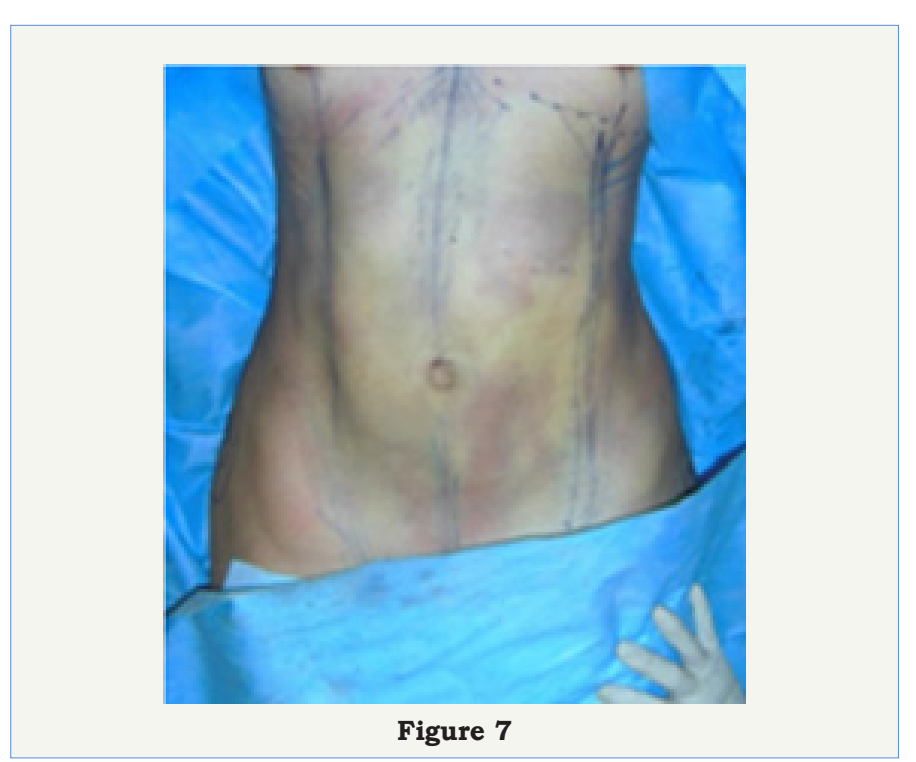


To achieve Di ANA for lipomarking, once the suction is at the right level, the implementation of the mechanical assisted liposuction is to delimit the desired retraction and the comprehensive redevelopment of the abdominal contour. Aspirated volume of bilateral areas must be approximately the same (Figure 8). No compressive bandage is applied at the end of the procedure.

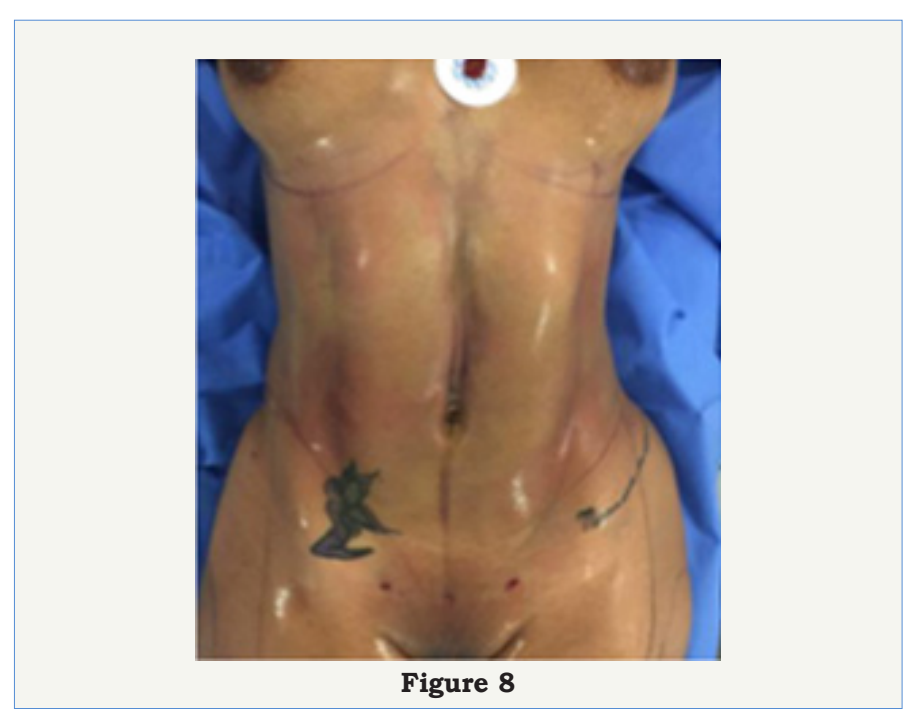

\section{Post-surgical management}

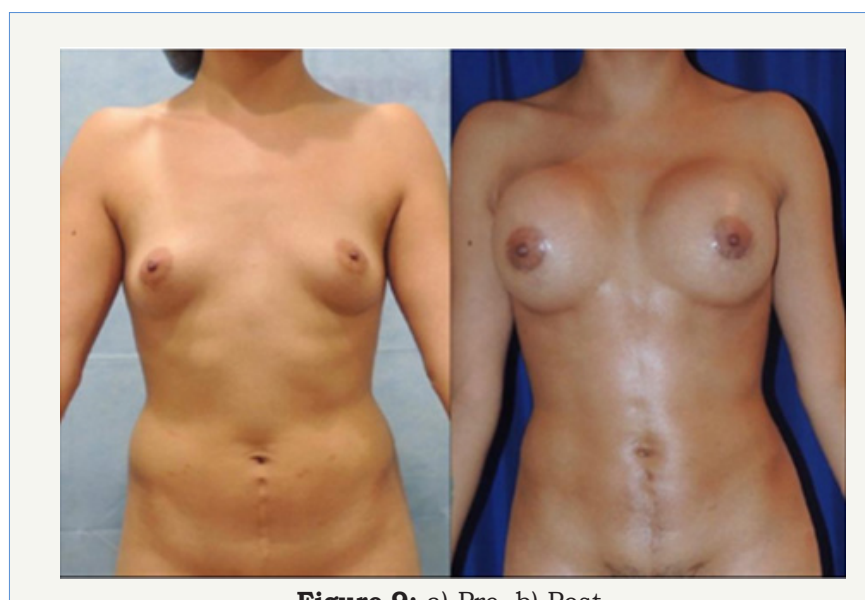

Figure 9: a) Pre, b) Post.

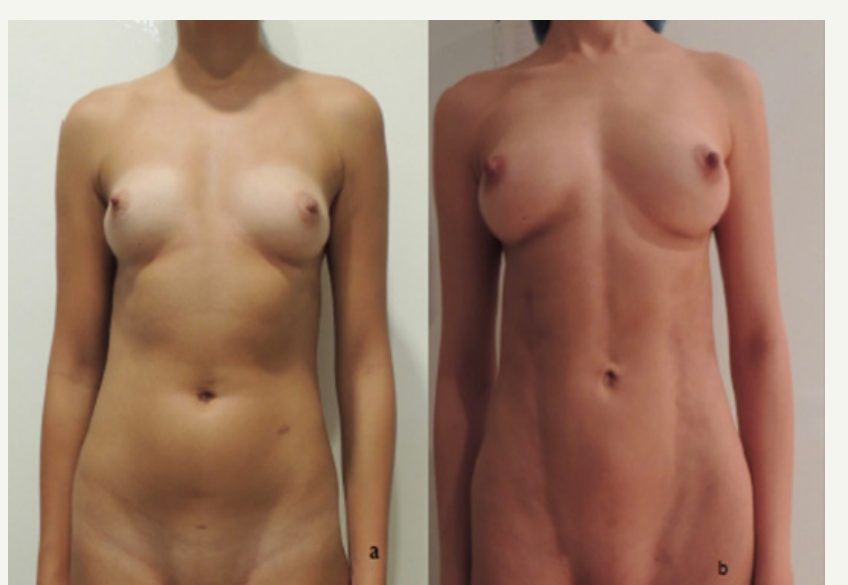

Figure 10: a) Pre, b) Post.
1. Start lymphatic drainage at 24 hours post liposuction for 10 days.

2. Once the bandage is removed (between 3 and 6 days post liposuction), the patient should continue using compression garments for about 8 weeks to promote a constant pressure of the operated area, which will reduce the inflammatory reaction and facilitate cutaneous retraction.

3. Ultrasound treatment should start on the fifth day (10 sessions recommended).

4. Initiate with radiofrequency from day 21 every $72 \mathrm{hrs}$. (10 sessions).

The final results are obtained between 2 and 4 months after the intervention, although changes are perceived from the sixth week.

\section{Clinical Cases (Figure 9-17)}
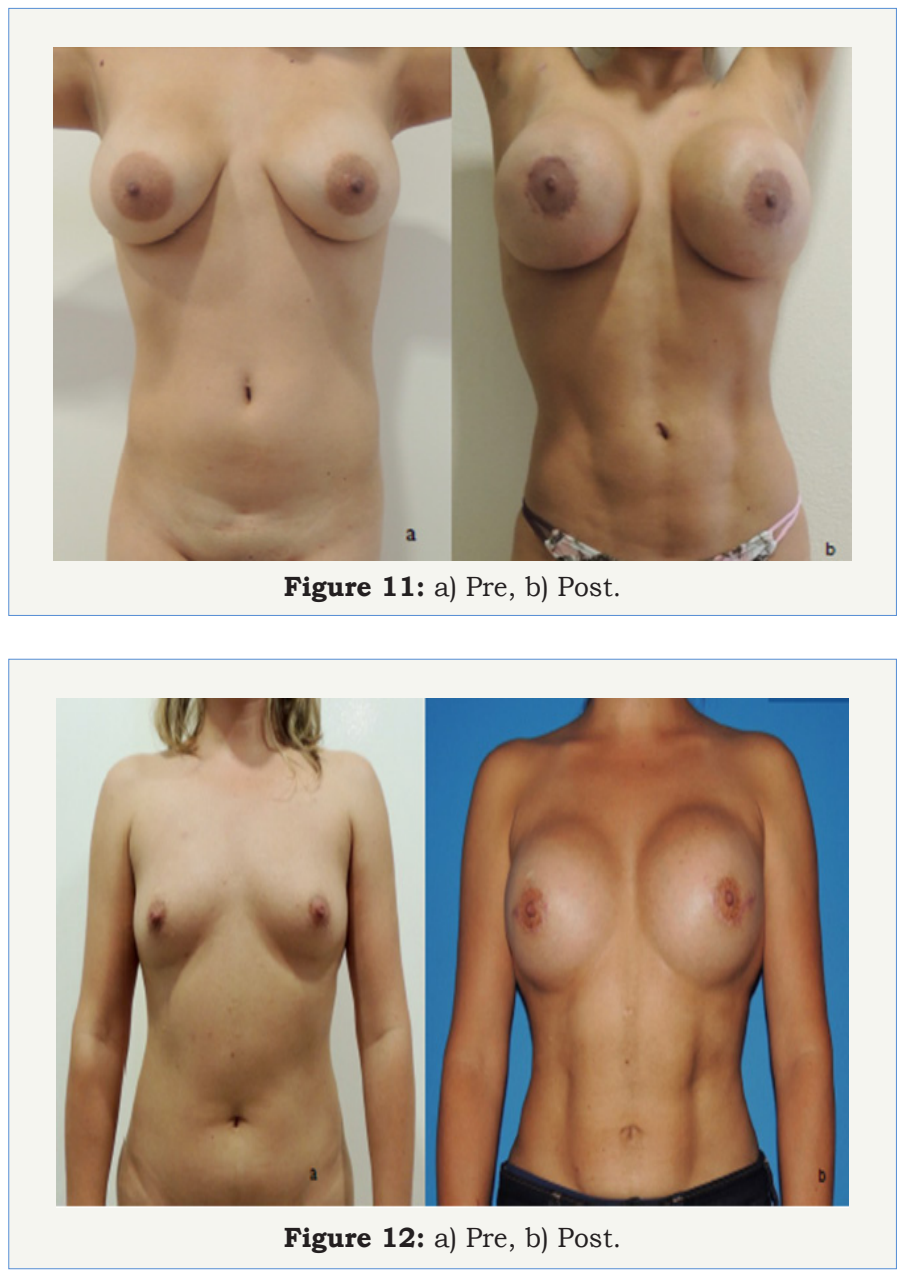

\section{Complications}

Oedema, dysesthesias and insatisfaction, rather than being complications are part of the process.

Infection: Infections are a rare complication when strict asepsis measurements are carried throughout the intervention.

Aesthetic: They are due to an incorrect indication or execution 
of the technique. Within which can be found: waste fat, depressions and irregularities.

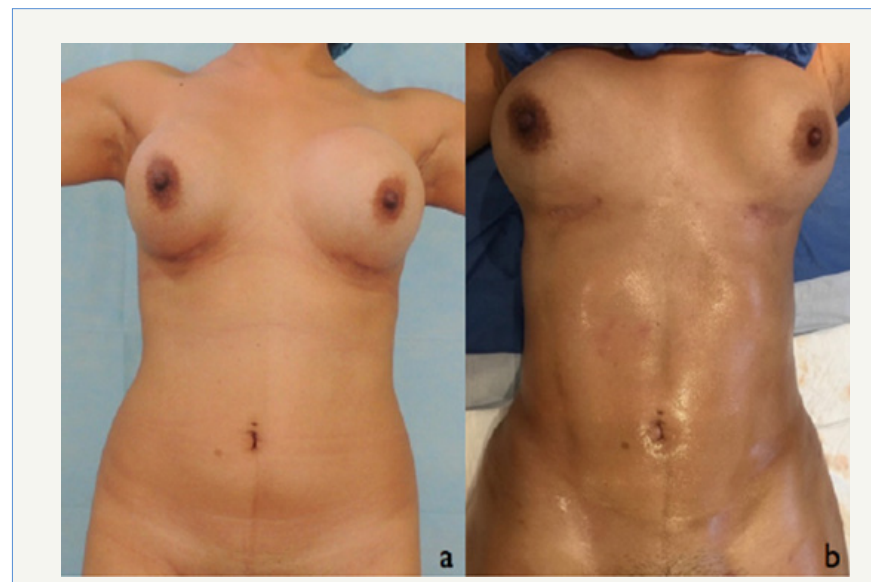

Figure 13: a) Pre, b) Post.

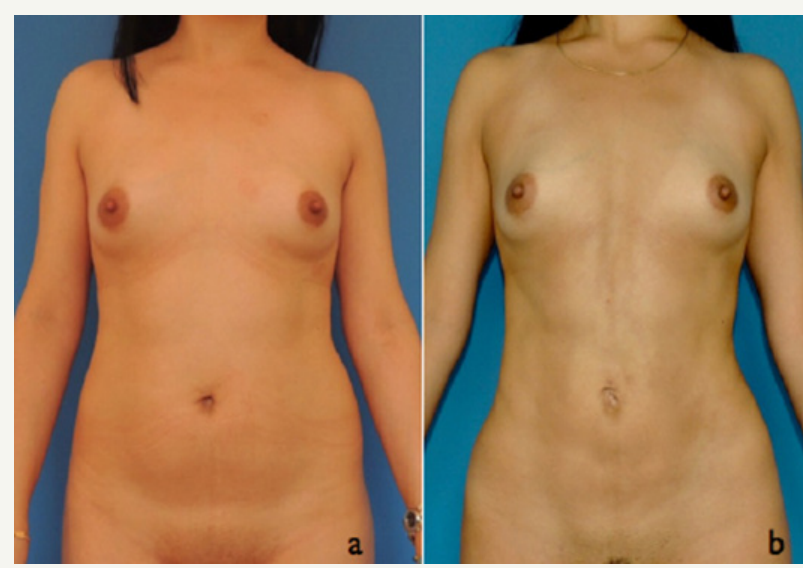

Figure 14: a) Pre, b) Post.

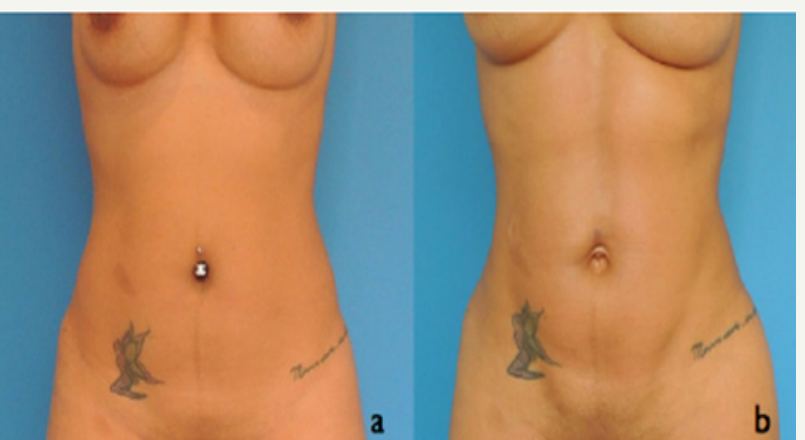

Figure 15: a) Pre, b) Post.

Derived from anesthesia: Those related to general or regional anesthesia (headache...) and cardiac and neurological consequences due to lidocaine toxicity.

Bruising. Blood loss: Hematomas in liposuction are consistent, depending more on capillary fragility than on the concentration of platelets or coagulation tests, although it is essential that they are within normal values. At cutaneous level, hematomas resolve spontaneously and in the worst cases, residual pigmentation may require cosmetic treatment.

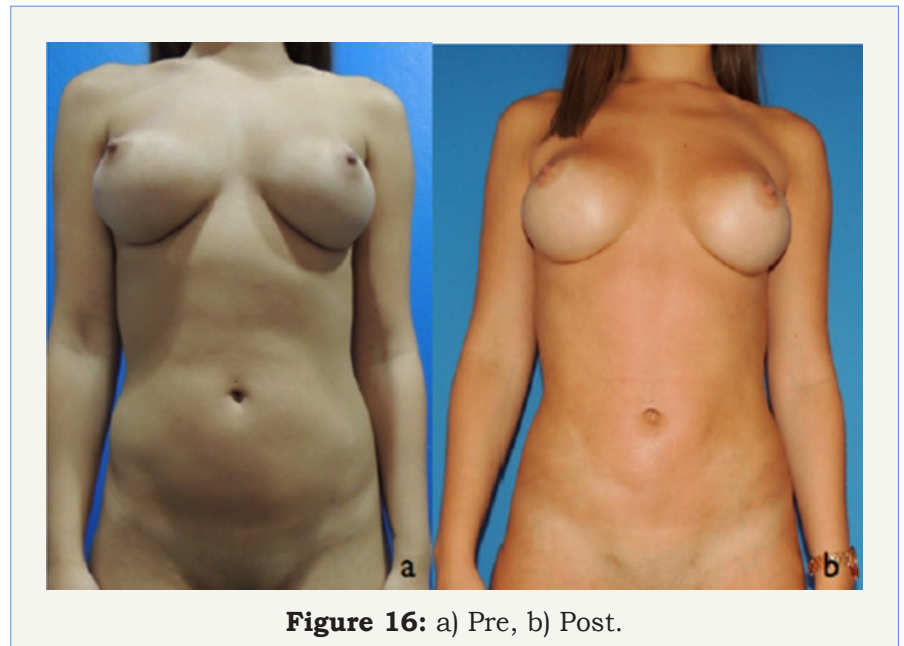

Figure 16: a) Pre, b) Post.

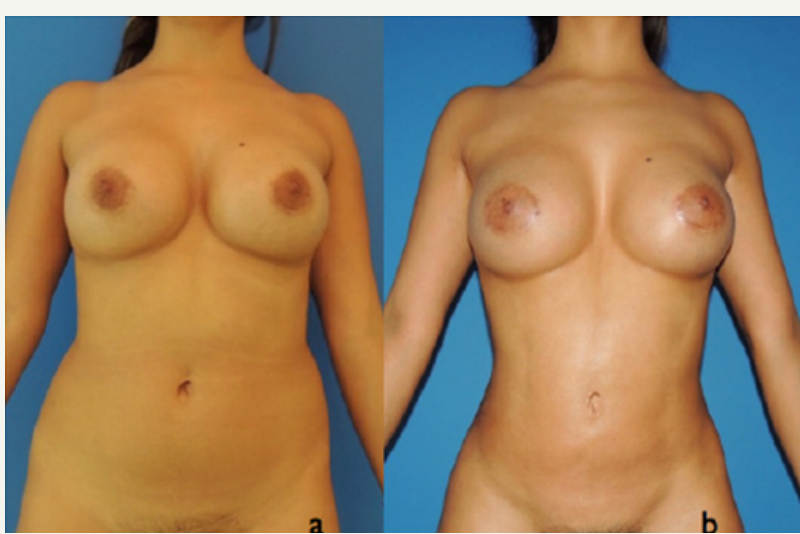

Figure 17: a) Pre, b) Post.

Embolism: Pulmonary thromboembolism is rare but is considered the leading cause of mortality for liposuction, being second to local anesthetic toxicity [9].

\section{Discussion}

The mechanical assisted liposuction and vibroliposuction are used to reduce fatty tissue and cause the adaptive natural marking in the abdomen. Di ANA for lipomarking offers the possibility of improved skin tension, removal of localized fat and a more streamlined abdomen. The end result in the abdomen will depend on the abdominal fatty and muscular tone of each patient.

\section{Conclusion}

The technique for lipomarking, which is described in this article, offers results by combining two procedures: mechanical assisted liposuction and mechanical vibroliposuction to delimit the abdominal contour, apparenting an exercised abdominal wall. This procedure is frequently requested by women patients who do not achieve these effects with exercise.

\section{References}

1. Coleman W (1990) The history of liposuction. Dermatol Clin 8: 381-383.

2. Fischer G (1990) Liposculpture: the "correct" history of the liposuction. Part I. J Dermatol Surg Oncol 16: 1087-1089.

3. Illouz YG (1998) Liposculpture et chirurgie de la silhouette. Encycl Méd 
Chir, Techniques chirurgicales- Chirurgie plastique recontructrice et esthétique pp. 45-120.

4. Fournier PF (1987) Body Sculpturing Through Syringe Liposuction and Autologous Fat Transplantation. Corona Del Mar, CA: Samuel Rolf International.o

5. Jewll ML, Fodor PB, Souza Pinto EB, Al Shammari MA. (2002) Clinica application of VASER-assisted lipoplasty: a pilot clinical study. Aesthetic Surgery Journal 22(2): 131-146.

6. DiGiuseppe A (2000) The harmonic lift: ultrasonically assisted skin remodeling. Int J Cosm Surg 2(2): 125-131.

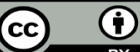

Creative Commons Attribution 4.0

International License

For possible submissions Click Here

Submit Article
7. Kloehn RA (1996) Liposuction with "Sonic Sculpture": Six years experience with more than 600 patients. Aesthet Surg J 16(2): 123-128.

8. Klein JA (2000) Pathophysiology and complications. In Tumescent Technique: Tumescent Anesthesia and Microcannula Liposuction. St, MO: Mosby pp. 25-120.

9. Dillerud E (1991) Suction lipoplasty: A report on complications, undesired results, and patients satisfaction based on 3511 procedures. Plast Reconst Surg 88: 239-246.

\section{Your subsequent submission with Crimson Publishers} will attain the below benefits

- High-level peer review and editorial services

- Freely accessible online immediately upon publication

- Authors retain the copyright to their work

- Licensing it under a Creative Commons license

- Visibility through different online platforms

- Global attainment for your research

- Article availability in different formats (Pdf, E-pub, Full Text)

- Endless customer service

- Reasonable Membership services

- Reprints availability upon request

- One step article tracking system 